\title{
Investigation of Optimum Jack-Up Vessel Chartering Strategy for Offshore Wind Farm O\&M Activities
}

\author{
Yalcin Dalgic ${ }^{1}$, Iraklis Lazakis ${ }^{1}$, Osman Turan $^{1}$, Sol Judah $^{2}$ \\ ${ }^{1}$ Department of Naval Architecture, Ocean and Marine Engineering, University of Strathclyde, Glasgow, UK \\ ${ }^{2}$ Global Maritime, Glasgow, UK
}

\begin{abstract}
Operating further from shore increases the logistic challenges of offshore wind Operation and Maintenance $(\mathrm{O} \& \mathrm{M})$ activities. Therefore, available vessels in the market and the variety of benefits \& drawbacks of different vessel chartering strategies have to be considered in the offshore wind O\&M planning. In contrast with the prospects, operating expenditure (OPEX) of the offshore wind farms has been increasing, reflecting greater risk for potential investors and current operators. In this context, significant cost reductions can be achieved through optimising the offshore related operations, considering the fact that vessel associated costs dominate the total OPEX of the projects. In this paper, the investigation of optimum chartering strategy for jack-up vessels, which indicates the influence of the chartering strategy, charter period, and the characteristics of the vessels involved in the operations, is introduced. Climate parameters, failure characteristics of turbine components, and the vessel specifications are synthesised in a time domain Monte-Carlo approach. The results can assist operators in developing long-term O\&M plans. Through this extensive study, it is concluded that optimum O\&M cost can be achieved by selecting optimum chartering strategy for jack-up vessels. In addition, regional collaborations between different offshore wind developers can be an alternative solution to reduce the O\&M costs.
\end{abstract}

Keywords: Offshore Wind, O\&M, Jack-up Vessel, Optimisation, Accessibility, Charter Rate, Seasonality

\section{Introduction}

During the operational span of an offshore wind farm, various scheduled and unscheduled maintenance tasks have to be performed in order to keep the turbines operational and to sustain the power production. Operation and Maintenance (O\&M) costs, which can constitute up to $30 \%$ of the overall offshore lifecycle cost, are three times higher than onshore (Blanco, 2009; Musial et al., 2010; Rademakers et al., 2003). The main cause of the substantial difference between offshore and onshore is the frequent need for utilising expensive transportation (Kaldellis and Kapsali, 2013). More complicated foundations, longer inter-array and export cables, harsher wind and wave conditions that limit the operability of vessels are the additional factors that escalate the cost of offshore wind projects.

Offshore wind levelised cost of energy reached $£ 140 / \mathrm{MWh}$ in 2011 (The Crown Estate, 2012); however the offshore wind industry has to commit

Corresponding Author: Yalcin Dalgic

Tel: +44 (0)141548 4778, +44 (0)141548 4094

Fax: +44 (0)141552 2879

E-mail Address: yalcin.dalgic@ @strath.ac.uk

Postal Address: Department of Naval Architecture, Ocean and Marine Engineering, University of Strathclyde, 100 Montrose Street, Glasgow G4 0LZ, United Kingdom to bringing the cost of offshore wind down to $£ 100 / \mathrm{MWh}$ in order to sustain the competiveness and the development in the offshore wind industry (WindPower Offshore, 2012). Previous studies have identified that the development of new O\&M vessels is particularly important; since the costs for vessels make up $73 \%$ of the total O\&M costs (Fingersh et al., 2006; Junginger et al., 2004; Krohn et al., 2009; Lazakis et al., 2013). Van Bussel and Zaaijer (2001) showed that irrespective of wind turbine design, the cost of lifting operations using a vessel accounted for more than $50 \%$ of the overall O\&M costs. Dinwoodie et al. (2013) evidenced that the proportion of vessel associated costs to the total O\&M costs is the largest; therefore, it is essential to keep the vessel cost optimum in order to achieve minimum cost of energy from offshore wind farms (Halvorsen-Weare et al., 2013). Due to the fact that financial benefit from generating more energy by increasing the availability does not always lead to higher profits, optimisation of vessel costs is the key to minimise the overall offshore wind project costs (Santos et al., 2014). 
In order resolve the issue of OPEX cost minimisation of offshore wind farm projects, the optimum jack-up vessel chartering strategy towards maximum economic and operational benefits is investigated. The paper is structured as follows; in Section 2, the common procedures, aspects and issues associated with offshore wind O\&M are presented. Through the observations in that section, a modelling methodology is specified in Section 3. A case study is presented in Section 4 to validate the developed model. In Section 5, the results of the case study are evaluated and concluding remarks are provided in Section 6.

\section{Literature Review}

\subsection{Available vessels in the market}

In the case of major component failures, small maintenance vessels are not adequate to perform the repair/exchange of damaged components. Therefore, one of the jack-up, leg-stabilised or heavy lift vessels have to be utilised, considering the properties of damaged component (weight, size, etc.), lifting height, and the capability of the vessel (lifting capacity, operational water depth, etc.). The characteristics of these major O\&M vessels are demonstrated in Table 1.

Jack-up vessels/barges are self-elevating units, which consist of a buoyant hull with a number of legs (generally 3 to 6 ). These vessels/barges are capable of station their legs on the sea floor, raising their hulls over the sea-surface, and provide stable environment for crane operations under rough sea/weather conditions. The operations of legstabilised vessels are very similar to the jack-up vessels/barges. Instead of lifting the hull over the sea surface, leg-stabilised vessels use their legs to stabilise the hull. Heavy lift vessels/barges are capable of lifting extensive loads, which can be experienced in offshore wind industry. These vessels possess the highest crane capabilities in offshore industry due to the fact that they are specially designed to install pre-assembled modules for the offshore oil and gas industry.

At this point, it is important to highlight the fact that the number of leg stabilised vessels is considerably low in the offshore wind market (EWEA, 2011). Furthermore, the daily charter rates of heavy lift vessels/barges are excessively high, which cause operators to consider other alternatives (DNV, 2004). Therefore, jack-up vessels/barges dominate the offshore wind energy market. However, the dependency on the offshore oil and gas industry result in issues associated with lower vessel availability and higher daily charter rates in demanding months (e.g. April to October). Therefore, advanced charter planning is crucial, especially as UK Round 3 projects and similar size forthcoming projects around the world are taken into account.

Table 1: Characteristics of offshore wind major O\&M vessels

\begin{tabular}{|c|c|c|}
\hline Vessel type & Benefits & Drawbacks \\
\hline Jack-ups & $\begin{array}{l}\text { - Specialisation for offshore wind farm projects } \\
\text { - Stable base for lifting operations } \\
\text { - Cost effective in medium and high wave areas } \\
\text { - Accommodation for both ship and maintenance } \\
\text { crew }\end{array}$ & $\begin{array}{l}\text { - Limited operational speed ( } 10 \text { knots }) \\
\text { - Capability to operate up to } 65 \mathrm{~m} \text { water depths } \\
\text { - Time consuming operations due to jacking up } \\
\text { and jacking down }\end{array}$ \\
\hline $\begin{array}{l}\text { Leg-stabilised } \\
\text { vessels }\end{array}$ & $\begin{array}{l}\text { - Ideal in shallow waters } \\
\text { - Quick transportation and installation capabilities } \\
\text { - Relatively lower daily charter rate }\end{array}$ & $\begin{array}{l}\text { - Limited number of vessels in the market } \\
\text { - Limited sea state capability }(\sim 0.5 \mathrm{~m}) \\
\text { - Risk of inadequacy due to increasing water } \\
\text { depths of the future projects }\end{array}$ \\
\hline Heavy-lifters & $\begin{array}{l}\text { - Very flexible for unusual cargoes } \\
\text { - Heavy lift capacity } \\
\text { - Larger deck area/space } \\
\text { - Relatively better stability characteristics }\end{array}$ & $\begin{array}{l}\text { - Low availability due to offshore oil \& gas } \\
\text { industry } \\
\text { - Slower mobilisation } \\
\text { - Port entrance limitations due to size } \\
\text { - Operations can be performed only in deep } \\
\text { water }\end{array}$ \\
\hline
\end{tabular}




\subsection{Alternative chartering periods and contractual arrangements}

The majority of the offshore wind farm operators do not prefer to own a jack-up vessel due to huge initial capital investment requirement. Therefore, these vessels are chartered for a limited period. Unplanned maintenance activities, catastrophic failures, and circumstances that require instant access to wind farms cause operators to hire vessels from the spot market for relatively short periods. In this context, short-term chartering is valuable for the wind farms that have sequential maintenance activities in a specified period. Longterm chartering requires advanced scheduling for the maintenance operations. In this case, the daily charter rate decreases; however the financial risks due to low utilisation become more significant. An alternative to reduce the risks is leasing the vessel to third parties, which can provide extra income for the operators.

With regard to contractual arrangements, voyage charter, time charter and bareboat charter are the commonly used three types of contractual arrangements in the maritime industry (Pirrong, 1993). The costs and individual responsibilities are distributed in a slightly different way (Figure 1). Under a voyage charter, the ship owner contracts to carry a specific cargo with a specific ship, which covers capital charges, daily running, and voyage costs. The time charter is an agreement between owner and charterer to hire the ship, complete with crew, for a fee per day, month or year. In this case, the ship owner pays the capital and operating expenses, whilst the charterer pays the voyage costs. As a final point, the bareboat charterer hires out the ship without crew or any operational responsibilities, so the charterer is responsible for daily running costs, voyage costs, O\&M costs and expenses related to cargo handling and claiming.

For short-term activities, time charter or voyage charter appear practical due to the difficulty to arrange crew, provide provisions and complete administrative jobs for short-term; on the other hand, bareboat chartering which provides more control on the costs elements, is a more feasible alternative for long-term operations.

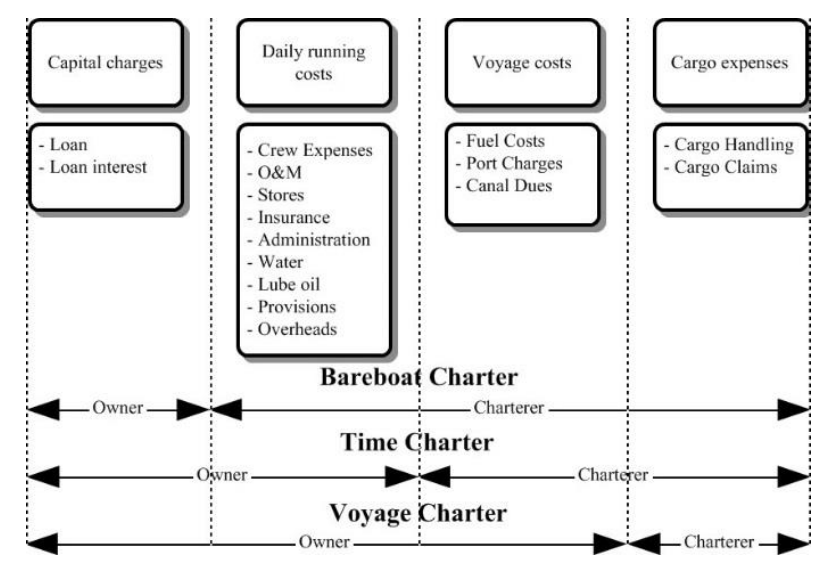

Figure 1: Vessel contractual arrangements

\section{Methodology}

In this section, the developed jack-up vessel chartering methodology is demonstrated with an attempt to synthesise and simulate the following five main calculation blocks; climate, failure, repair, power calculation and finally cost calculation (Figure 2). In addition, there are four input sections which provide information for these calculation blocks.

In the following sections, vessel chartering, vessel specification, cost specific attributes, and wind farm/turbine specific attributes are introduced in the first place and the phases where these inputs are considered during the simulations are explained. Secondly, the following major calculation blocks; failure, repair, power calculation, and cost calculation blocks are introduced to present the simulation logic.

\subsection{Input blocks}

\subsubsection{Vessel chartering}

\subsubsection{Short-term charter}

Short-term charter (spot market) is modelled as time charter in which the total O\&M cost comprises of fuel cost, mobilisation cost, daily charter payments; in addition Original Equipment Manufacturer (OEM) cost for the component replacement are added to the total O\&M costs. Fuel cost, which is dependent on the fuel consumption of the jack-up vessel and the utilisation of the vessel, is modelled separately for the days which the jackup vessel is in port and in operation. 


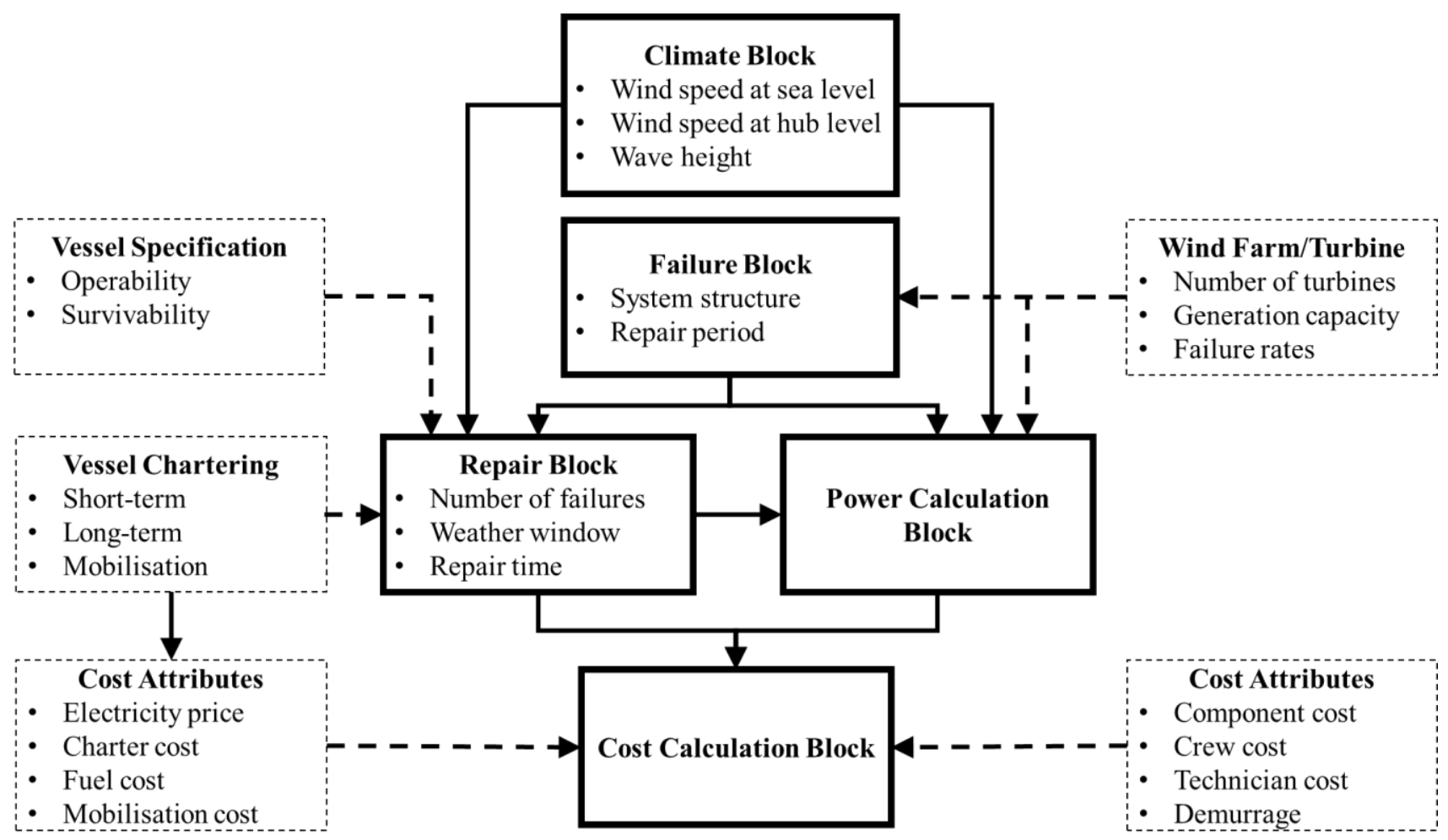

Figure 2: Proposed methodology

Mobilisation cost is often paid to compensate the vessel owner for the time and the expenses to get the vessel on site, prepared and ready for work. The vessel owner will then charge by day rate as the vessel is used. In this respect, Kaiser and Snyder (2010) presented the cost of jack-up mobilisation as a function of distance, vessel day rate, vessel size, and transport method. From time point of view, the mobilisation time has a significant influence on the mean time to repair (MTTR) values of the components and the availability of the turbines. In the developed model, mobilisation cost and mobilisation time are defined through selecting a random value from an equal weighted mobilisation time and mobilisation cost dataset. Due to the fact that the mobilisation time and the mobilisation cost are not constant values and may vary in each contract depending on the supply and the demand at the specified year, these variables are defined separately for each theoretical charter contract in order to preserve the random behaviour of the mobilisation time and the mobilisation cost. The sampling procedure involves choosing random sample with replacement considering that every value is returned to the dataset after sampling; therefore the values, which are selected for a charter contract, can be selected again for the subsequent contracts.

The mobilisation time and the mobilisation cost are taken into account if the charter contract is not signed yet. If a jack-up vessel is already available on the site for another repair or if a major failure occurs during the mobilisation period for another maintenance activity, the mobilisation cost will not be considered for the subsequent maintenance activity. Similarly, if there is a jack-up vessel available on the site, the mobilisation time will not be considered for the subsequent maintenance activity; however the mobilisation time will be considered as the remaining mobilisation time for the first maintenance activity if the subsequent failure occurs within the mobilisation time of the first failure.

Jack-up vessel charter cost is calculated considering the daily charter rate and the agreed charter period. When the charter period is completed, the vessel leaves the site if all the repairs/replacements are completed within the charter period. In the developed model, the priority is the maximisation of the power generation; therefore if another repair needs to be performed, the vessel navigates to that turbine regardless of the 
remaining charter period. In this context, if the planned O\&M activities cannot be completed in the charter period, demurrage cost, which is the money payable to the vessel owner for delay beyond the agreed charter period, is added to the total O\&M cost. If the remaining charter period is shorter than the required repair time, demurrage is paid subject to the extension on the charter period. Demurrage is assumed to be a function of vessel day rate.

\subsubsection{Seasonality in charter rates}

The daily charter rates of jack-up vessels vary considerably depending on the season in which the operators/developers intend to hire the vessels. The O\&M activities are more likely to be suspended by the challenging weather conditions in winter. On average, the wind speeds in winter are generally higher than the wind speeds in summer. Therefore, the power production in winter is expected to be higher than the power production in summer; however this situation causes higher revenue loss in case of failure. On the contrary, monthly capacity factors show lower trend in summer seasons, which also decrease the power production and it is unlikely the O\&M activities to be suspended due to weather in summer (Rademakers and Braam, 2002). Due to these reasons, operators plan O\&M activities in summer months, which increase the demand and eventually the daily charter rates of jack-up vessels (Dalgic et al., 2014; The Crown Estate, 2014).

In this respect, the jack-up charter rates are modelled separately for summer and winter, which are defined by the month that the chartered jack-up vessel arrives on the site. Summer denotes the period between April and September, inclusive; winter denotes the period between October and March, inclusive.

\subsubsection{Long-term charter}

Long-term charter is modelled as bareboat charter; therefore fuel cost, crew expenses, technician salaries and jack-up vessel O\&M costs are taken into account, additional to the daily charter rate of the jack-up vessel. Furthermore, a separate management team is considered, which is responsible from only vessel management to keep the vessel operating.
The crew expenses, technician and management team salaries are expected to be paid throughout simulation period, whether the jack-up vessel is utilised or not. Jack-up vessel O\&M cost is modelled as dry dock cost which occurs once in 2.5 years. In order to investigate the sub-chartering opportunity, the number of sub-charters within a year and related sub-charter period are modelled. In this respect, it is assumed that the O\&M activities are never delayed due to sub-charters.

\subsubsection{Vessel specification}

The second input block to be considered is the vessel specification block which comprises of vessel operability and vessel survivability. Operability and survivability limitations of the chartered jack-up vessel is governed by the wind speed and the wave height values. It is assumed that the jack-up vessel is capable enough to perform all the specified major O\&M activities in terms of crane capacity and operational water depth.

Vessel survivability is modelled considering wind speed values at sea level and wave height values. Vessel operability is modelled in two sequential steps; jacking up/down and actual repair. Wind speed at sea level and wave height are taken into account for jacking up/down operations. When the jack-up vessel completes the jack-up operations, the actual repair operations are dependent on wind speed values at hub height; considering the vessel survivability is the major prerequisite to start/perform the O\&M activity.

\subsubsection{Cost specific attributes}

Vessel charter rate, vessel mobilisation, demurrage, fuel, dry-docking, crew, technician and management costs comprise the vessel specific cost attributes. The details regarding which cost attribute is considered depending on the charter type are explained in the vessel chartering section. Electricity price is utilised in the revenue calculations. Component Original Equipment Manufacturer (OEM) costs are also considered in the model. Different inflation rates can be defined for each cost attribute, considering the fact that component prices may decrease due to technological development and advancements in the component production; on the other hand staff 
costs may increase due to increase in the demand for crews.

\subsubsection{Wind farm/turbine specific attributes}

Wind farm/turbine specific attributes are the number of wind turbines in the wind farm, the power production values for associated wind speeds, and the time dependent hazard rates of the turbine components. These attributes influence the number of failures and the total power production of the wind farm. In addition, hub height from sea level is required to extrapolate wind speeds from observation height to hub height.

\subsection{Calculation blocks}

\subsubsection{Climate block}

In climate block, wind speed at sea level, wind speed at hub level and wave height datasets are created to provide information for repair and power calculation blocks. Whilst all the generated datasets provide information for the repair block, wind speed at hub height dataset also provides inputs for the power calculation block.

In the first stage, it is intended to generate different climate datasets for each simulation, which include wind speed and wave height values, ensuring the general characteristics (e.g. mean, variance) of the original dataset are preserved. In this respect, the original dataset, which includes wind speed and wave height observations, is divided into multiple yearly datasets, number of which is defined by the duration of the original dataset, $L_{\text {org }}$ (years). All the divided datasets comprise wind speed and wave height observations together within a period of 1 year. In order to preserve the correlation between wind speed and wave height observations, these datasets are not disjointed from each other.

In the second stage, a discrete uniform distribution, which defines equal weights on the integers from 1 to $L_{\text {org }}$, is utilised for random sampling process. In this respect, each integer symbolises one of the pre-divided datasets; thus the selection of an integer indicates the selection of a pre-divided dataset which is represented by that integer. The sampling procedure involves choosing random samples with replacement which means that every sample is returned to the dataset after sampling. So a particular integer from the original dataset could appear multiple times. Random sampling continues until the number of randomly selected integers becomes equal to the defined simulation period, $L_{\text {sim }}$ (years). The order of the selected integers defines the form of the generated dataset which is utilised in the simulation. This procedure is repeated for each simulation to sustain unpredictability of the climate parameters.

It is envisaged that the jack-up operations may cease due to extreme winds at sea level and also hub level. Therefore, it is required to extrapolate the wind speed observations into the wind speed values at specified altitudes. Moreover, it is essential to calculate the wind speed values at hub level in order to calculate the power production. In this respect, Gryning et al. (2007); Lackner et al. (2010), and Gualtieri and Secci (2012) proposed different methods to extrapolate the wind speed observations to different wind speed values at different altitudes. Wind Power Law is the most widely used method among these methods (Firtın et al., 2011), which is presented in Equation 1;

$$
v_{2} / v_{1}=\left(h_{2} / h_{1}\right)^{\alpha}
$$

where $v_{2}$ is wind speed at altitude $h_{2}, v_{1}$ is wind speed at reference height $h_{1}$. The shear exponent $\alpha$ varies depending on atmospheric conditions, temperature, pressure, humidity, time of the day and nature of terrain (Manwell et al., 2009). The shear component can typically be assumed to be equal to 0.1 in offshore environment (Bechrakis and Sparis, 2000; Burton et al., 2011).

\subsubsection{Failure block}

Time dependent hazard rates are analysed within failure block from which mean time between failures (MTBF) and mean time to repair (MTTR) values are provided to the power calculation block. A time domain Monte-Carlo approach has been adopted, which relies on random number generation to ensure that all possibilities are covered in an unbiased manner. Such an approach requires deterministic and stochastic events. While the deterministic events are directed by the inputs and the assumptions; the stochastic events are comprised by turbine failures and weather 
conditions. During the simulations, a random number between 0 and 1 is generated from a uniform distribution for each time step. If the generated random number is smaller than the system hazard rate at the specified time step, the turbine is changed to failed state at the specified time step; otherwise continues functioning. The hazard rate at time $t h(t)$ is the ratio of the probability density function $P(t)$ to the survival function $R(t)$.

$$
h(t)=P(t) / R(t)
$$

The component configuration of the turbine is considered as a series system, which the turbine can function if and only if all components are in the functioning state. In this context, the system hazard rate $h_{\text {system }}(t)$ at the time step $t$ is equal to the summation of the component hazard rates $h_{\text {component }}(t)$ at the time step $t$.

After identifying the time step that the turbine is failed, it is required to identify which component is the cause of the failure. In this respect, weights are assigned to each component. The value of each weight is defined by the contribution of component hazard rates to the overall component hazard rate at the failure time step. Considering the assigned weights, a random selection is performed to identify the failed components. Due to the fact that the component with higher hazard rate has higher weight, it is more likely that this component causes the failure of the wind turbine.

\subsubsection{Hazard rate progress}

At the beginning of each simulation, the time steps of the first failures and the components that are failed for each turbine are identified. A jack-up is allocated for the turbine which fails first and the repair is performed. The details about the repair action is explained in the following section. When the failure is repaired and the time step at which the turbine starts functioning again is identified, the hazard rate of the failed component is reset to the initial level, as the repaired component is assumed 'as good as new' condition. The hazard rate distributions of other components are shifted forward to the time step which the turbine starts to function, considering the fact that other components are remained untouched within the repair period.
The hazard rate of the system is updated considering the updated component hazard rates and a new Monte-Carlo simulation is run from the time step at which the turbine starts to function until the end of the simulation period through using the updated hazard rate distribution of the system. As a result of the new Monte-Carlo simulation, the subsequent failure of the turbine is identified. If there is no subsequent failure for that specific turbine or the time is not enough to repair the failure within the simulation period, the following failure type of that specific turbine is set to infinity (INF).

The simulations continue until all the subsequent failure types for all turbines are set to INF, which indicates that either any new failure will not occur after that specific time step or the current failures cannot be repaired which also means that a failure cannot occur because the condition of the turbine will not change from failed state to functioning state.

\subsubsection{Repair block}

The major repair/replacement restrictions comprise surviving, jacking and operating constraints. In extreme storm conditions, the jackup vessel cannot sail, operate or perform any maintenance activity due to high risk of sinking and capsizing. In this case, the vessel has to be kept in the specified port. It is assumed that the major repairs cannot be suspended after repair activity is started; therefore the jack-up vessel can only start the O\&M activity, if there is no expected storm during repair period. Storm conditions are defined by limiting significant wave height $\left(\mathrm{H}_{\mathrm{s}}\right)$ and wind speed at sea level.

In order to start jacking-up operation, the minimum weather window should be longer than the time required for jacking-up. In this case, the minimum weather window is defined by the consecutive time-steps in which $\mathrm{H}_{\mathrm{s}}$ and wind speed values are lower than the limiting $\mathrm{H}_{\mathrm{s}}$ and wind speed for jacking operation. If the minimum weather window is shorter than the jacking-up period, the vessel waits on the site until the conditions are met. When the minimum weather window is sufficient enough, the vessel jacks-up. 
Due to the fact that the major O\&M activities require heavy equipment lifting, wind speed at hub level is an extra limitation for the jack-up operations. As like jacking operation, the minimum weather window should be longer than the time required to perform the repair or the replacement. If the weather window is shorter than the repair period, the vessel waits as jacked-up until the conditions are met. It is expected that the technicians work on 3-shift cycle; therefore the repair activities continue 24 hours/day. After completing repair, the vessels can only start jacking-down if the weather window is sufficient enough to complete the jacking-down. During mobilisation, jacking-up, actual repair, jackingdown periods, the turbine remains inactive; the turbine starts functioning again 1 time-step after the repair/replacement is completed. A time-step denotes the period of the climate observations (preferably 1-hour or lower).

\subsubsection{Power calculation block}

In the power calculation block, the time steps that the turbines produce power are identified. Considering the wind speed at hub height values, the total power produced in each time step is calculated. In this context, the wake effect is neglected and the wind speed is assumed uniform within the offshore wind farm.

\subsubsection{Cost calculation block}

Cost calculation block is the final section where all the information from previous blocks is collected and outputs are generated to support the optimisation jack-up related offshore O\&M activities. Charter cost is paid to the vessel owner continuously within agreed period, even though the utilisation level of the vessel can be low. The fuel cost is calculated depending on how frequent the vessel is used. All the cost attributes are calculated individually for each charter period in each simulation and averaged when the simulations are completed.

\section{Case study}

To evaluate the accuracy of the developed model, a case study is performed. Optimum charter periods are investigated for three potential UK
Round 3 offshore wind farms, which consist of 100 , 200, and 300 turbines. 1000 simulations are run in order to cover different variations in the results due to the randomisation of variables in the MonteCarlo simulation process. A $3 \mathrm{MW}$ turbine is considered in the simulations. Power curve and summary statistics of a 3MW turbine are presented in Staffell (2012). The offshore wind turbine is considered to consist of 4 different major components (blade, generator, gearbox, and transformer), which form a series turbine system.

In order to demonstrate the development and change of hazard rates throughout the simulation period, all the constant hazard rates, which are presented by Lindqvist and Lundin (2010), are modified to time dependent hazard rates that are denoted by individual 2 parameter (shape $k$, scale $\lambda$ ) Weibull distributions (Table 2). In this case, the mean of the Weibull hazard rate distributions are equal to the constant hazard rates provided by Lindqvist and Lundin (2010). In addition, OEM costs and repair duration of specified components, which are presented by Lindqvist and Lundin (2010), are shown in Table 2. The component and system hazard rate distributions, which are created by the Weibull parameters in Table 2, are graphically presented in Figure 3. At this stage, it is important to highlight that the knowledge and experience related to reliability figures and the hazard rates of offshore wind turbine components are very limited, therefore, it should be possible to utilise more accurate offshore wind hazard rates in the future.

Table 2. Component failure and repair specifications

\begin{tabular}{|c|c|c|c|c|}
\hline & Blade & Gearbox & Generator & Transf. \\
\hline Repair Cost (£) & 75,000 & 400,000 & 120,000 & 42,000 \\
\hline Repair Time (h) & 24 & 144 & 72 & 144 \\
\hline Infant $\lambda$ & 1 & 1 & 1 & 0.7 \\
\hline Infant $\mathrm{k}$ & 0.0015 & 0.05 & 0.015 & 0.013 \\
\hline Random $\lambda$ & 280 & 30 & 25 & 100 \\
\hline Random k & 1 & 1 & 1 & 1 \\
\hline Wear $\lambda$ & 30 & 24 & 24 & 24 \\
\hline Wear k & 10 & 14 & 15 & 19 \\
\hline
\end{tabular}


Major Hazard Rate Distributions of Turbine System and Components (Initial)

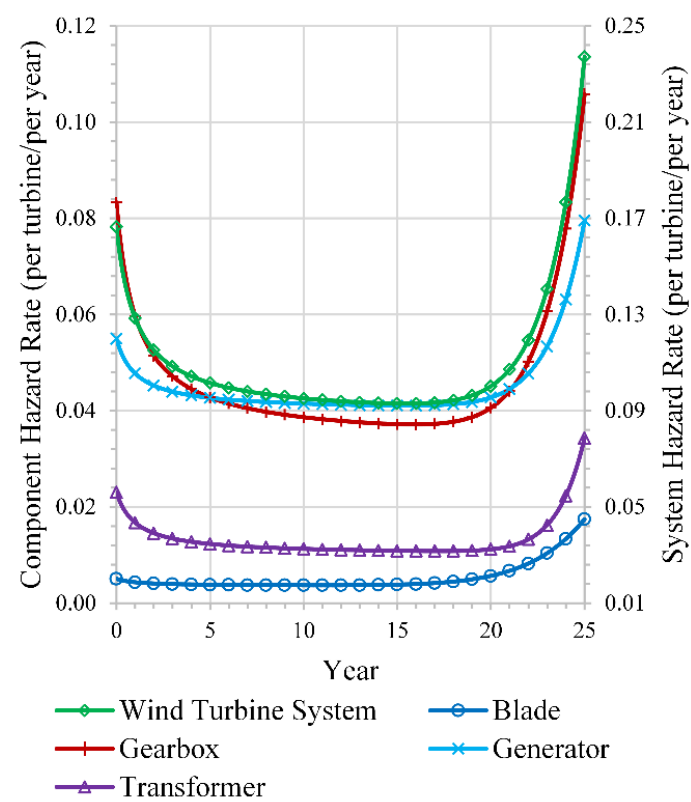

Figure 3: Initial turbine system and component time dependent hazard rates

The operability and survivability limitations of the jack-up vessel are reported by MPI Offshore (2013), and also presented in Table 3. The jack-up vessel can only travel to offshore wind farm, if the wind speed at sea level and wave height values within repair period are lower than $36.1 \mathrm{~m} / \mathrm{s}$ and 10 $\mathrm{m}$, respectively. The jacking-up and jacking-down operations can be done if the wind speed at sea level and wave height values are lower than $15.3 \mathrm{~m} / \mathrm{s}$ and $2.8 \mathrm{~m}$, respectively. After completing jacking-up operation, the wind speed values at hub level should be lower than $20 \mathrm{~m} / \mathrm{s}$ within repair period in order to start the actual O\&M.

Table 3: Jack-up vessel limitations

\begin{tabular}{lll}
\hline & Operability & Survivability \\
\hline Wind speed at hub level & $20 \mathrm{~m} / \mathrm{s}$ & - \\
Wind speed at sea level & $15.3 \mathrm{~m} / \mathrm{s}$ & $36.1 \mathrm{~m} / \mathrm{s}$ \\
Wave height & $2.8 \mathrm{~m}$ & $10 \mathrm{~m}$ \\
\hline
\end{tabular}

In the simulations, charter periods up to 1 year (52 weeks) with weekly intervals are considered for the short-term charter option. For the long-term charter option, a period of 25 years, which theoretically covers the entire lifecycle of an offshore wind farm, is taken into account. Table 4 presents the short-term charter related parameters. It is envisaged that the fuel consumption of the jackup vessel is 10 tons/day during operations and 2 tons/day if the vessel stays at the port. The daily charter rates for the specified jack-up vessel are defined as $£ 172,500 /$ day during summer (AprilSeptember) and $£ 116,250 /$ day during winter (October-March); as seasonal changes in the daily charter rates are expected due to variations in supply and demand (Dalgic et al., 2014). Although the demurrage rate is an arbitrary figure agreed between the vessel owner and the charterer (Edkins and Dunkley, 1998; Wilson, 2010), as being reasonable for the state of the shipping market for the purpose of this paper it is assumed as a $30 \%$ increase in the daily charter payments. The above demurrage rate is considered until all repairs are completed and the jack-up vessel leaves the site if the agreed charter period is not enough to complete all the repairs. Due to the fact that daily charter rates are different for summer and winter; the demurrage rates are also different. Mobilisation costs are adopted from Kaiser and Snyder (2010), and converted to British Sterling with an exchange rate of $£ / \$ 1.68$ in Table 4.

Table 4: Jack-up charter parameters - short-term charter

\begin{tabular}{ll}
\hline Parameter & Value \\
\hline Fuel consumption in port & 2 tons \\
Fuel consumption in operation & 10 tons \\
Daily charter rate & $£ 172,500$ (summer) \\
Demurrage & $£ 116,250$ (winter) \\
& $+30 \%$ daily rate \\
Mobilisation cost & $£ 114,000-10$ months \\
and & $£ 229,000-8$ months \\
Mobilisation time & $£ 473,500-6$ months \\
& $£ 686,500-4$ months \\
\end{tabular}

Table 5 presents the long-term charter related parameters. The fuel consumption rates are identical to the spot charter section values. It is envisaged that the jack-up vessel is sub-charted 2 times in every simulation year. The daily charter and sub-charter rates for the jack-up vessel are demonstrated in Dalgic et al. (2014), which can also be found in Table 5 .

Table 5: Jack-up charter parameters - long-term charter

\begin{tabular}{ll}
\hline Parameter & Value \\
\hline Number of sub-charters per year & 2 \\
Sub-charter period & 15 days \\
Daily sub-charter rate & $£ 160,400$ \\
Crew + Technicians + Management Team & 40 people \\
Average annual salary & $£ 70,000$ \\
(Crew + Technicians + Management Team) & $£ 67,800$ \\
Daily charter rate & $£ 1,000,000$ \\
Dry-docking cost & \\
\hline
\end{tabular}


Table 6 shows the additional parameters which have to be defined before running the simulations. For the cost calculations 5\% inflation rate is considered; therefore, electricity price, technician salaries, jack-up charter payments, mobilisation costs, and demurrage will be increased as the defined inflation rate each year within the simulations. Low sulphur marine gas oil price is based on current market prices.

Table 6: Additional input parameters

\begin{tabular}{ll}
\hline Parameter & Value \\
\hline Electricity price & $140 £ / \mathrm{MWh}$ \\
Turbine capacity & $3000 \mathrm{~kW}$ \\
Number of turbines & $100-200-300$ \\
Observation point from sea level10 m \\
Hub level from sea level & $105 \mathrm{~m}$ \\
Wind shear component & 0.1 \\
Inflation rate & $+5 \% /$ year \\
Low sulphur marine gas oil & $550 £ /$ ton \\
Jack-up/down period & 3 hours \\
\hline
\end{tabular}

\section{Results}

In this section, the results of the O\&M simulations are presented, considering the specific information provided in the case study section. It is important to highlight that these results are strongly related to the values provided; therefore, the final results and eventually the optimum chartering strategy identified can change if the values in the inputs block are changed. Figure 4 is a sample graphical representation in order to demonstrate the progress of the time dependant hazard rates within the simulation period. In this specific example, the major turbine components failed 3 times within 25 years.
Major Hazard Rate Distributions of Turbine System and Components (Updated)
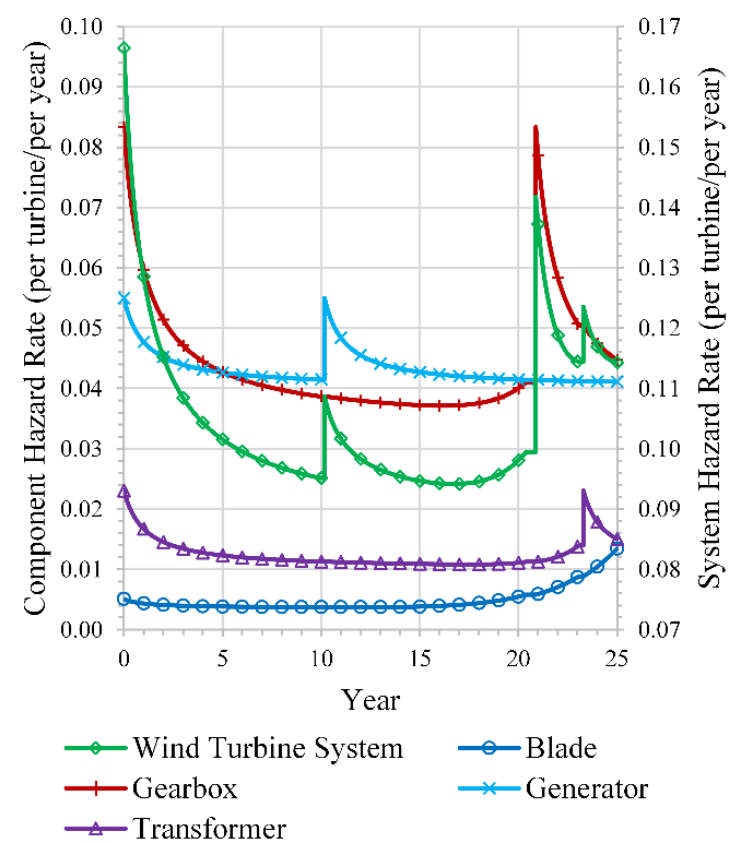

Figure 4: Updated turbine system and component time dependent hazard rates

The generator failed around year 10; after the repair of the generator, the hazard rate of this component is reset and the wind turbine hazard rate is updated, while the blade, the gearbox, and the transformer hazard rates are kept at the same level as in the time step that the turbine is failed. The second failure, which the gearbox is failed, occurred around year 21. In this case, a jack-up vessel is not available on the site; therefore a mobilisation time is awaited to start the repair of the failed component. The mobilisation time can be noticed from the straight lines in the time dependent hazard rate distributions. After the mobilisation and actual repair periods are completed, the hazard rate of the gearbox is reset and the hazard rate of the wind turbine system is updated, while the blade, the generator, and the transformer hazard rates are kept at the same level as in the time step that the turbine is failed. The transformer failed in year 23. Similar procedure is followed for the transformer failure. It has to be highlighted that Figure 4 represents one turbine in one simulation; due to the randomisation of variables in Monte-Carlo simulations, the progress of the component and the system hazard rates are unique for each turbine in each simulation. 
Based on the long-term charter section of the case study, the total O\&M cost, which is composed of the total fuel, total OEM, the total staff, and the total charter costs, increases when the size of the wind farm increases (Figure 5). However, the increase in the total O\&M cost is not as high as the increase in the wind farm size. This is because, only the total OEM costs are proportional to the wind farm size but they only account for $7.9 \%, 14.6 \%$ and $20.4 \%$ of the total O\&M costs for 100-turbine, 200-turbine and 300-turbine sites, respectively. On the other hand, the total charter costs for 100turbine, 200-turbine, and 300-turbine wind farms account for $80.3 \%, 74.0 \%$, and $68.6 \%$ of the total O\&M costs, respectively. $1.5 \%, 1.9 \%$ and $2.2 \%$ of the total O\&M costs are paid for the fuel costs for the 100-turbine, 200-turbine, and 300-turbine wind farms, respectively. $£ 16.8$ million is paid within 25 years for the jack-up vessel's maintenance in both cases. £229.6 million sub-charter revenue can be gained in all cases, considering the fact that the jack-up vessel is sub-chartered 2 times for 15 days in each year of the simulations. This revenue from sub-chartering can be increased with an improved vessel management and charter planning.

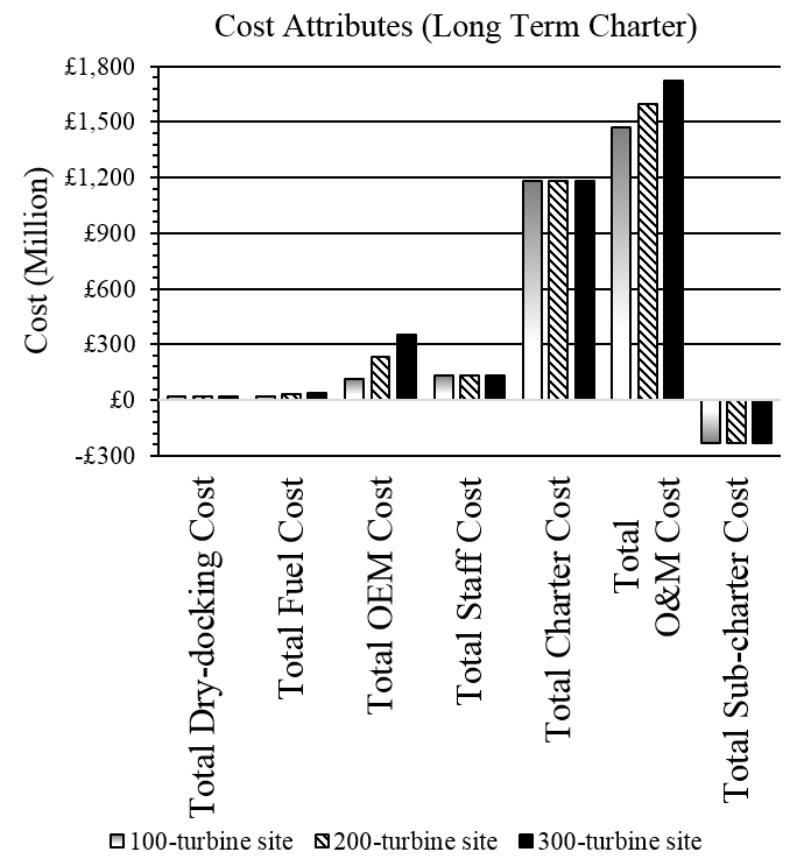

Figure 5: Cost attributes for long-term charter

Vessel utilisation is the proportion of actual vessel usage to the total charter period. It can be noticed that the vessel utilisation increases significantly when the number of turbines in the offshore wind farm increases (Table 7). Total O\&M Cost/MWh denotes the O\&M cost per unit production. In this context, the total O\&M cost/MWh (including loss revenue) decreases when the number of turbines in the offshore wind farm increases. When the MTTR values are taken into account, an increase can be observed for the larger offshore wind farm cases. The reason of the increase in MTTR values is due to simultaneous failures that may occur more likely in larger wind farms.

Table 7: Other attributes and MTTR values for longterm charter

\begin{tabular}{lccc}
\hline Attribute & \multicolumn{3}{c}{ Number of Turbines } \\
& 100 & 200 & 300 \\
\hline Vessel Utilisation (\%) & 14.4 & 28.8 & 43.2 \\
Total O\&M Cost/MWh (£/MWh) & 67.6 & 37.1 & 27.1 \\
Blade-MTTR (hours) & 47.9 & 65.9 & 95.8 \\
Gearbox-MTTR (hours) & 167.9 & 184.8 & 211.9 \\
Generator-MTTR (hours) & 96.1 & 112.6 & 139.2 \\
Transformer-MTTR (hours) & 167.9 & 185.7 & 213.6 \\
\hline
\end{tabular}

In respect to short-term aspects, Figure 6-8 present the O\&M cost distributions for the defined wind farms. In short-term chartering, the total vessel charter costs contribute most to the total O\&M costs, similar to the cost attributes for longterm chartering. The short-term charter periods, which the total O\&M costs are minimum, are identified as 3, 7, and 16 weeks for 100-turbine, 200-turbine, and 300-turbine cases, respectively. On average, the total fuel cost, the total OEM cost, the total charter cost, and the mobilisation account for $1.2 \%, 10.4 \%, 86.0 \%$, and $2.4 \%$ of the total O\&M cost for the 100-turbine case, respectively (Figure 6). Similar to the 100-turbine site figures, the total fuel cost, the total OEM cost, the total charter cost, and the mobilisation cost for the 200tubine case account for $1.5 \%, 15.9 \%, 80.8 \%$, and $1.8 \%$ of the total O\&M cost, respectively (Figure 7). The values for the 300-turbine case show similarity to the other cases; the total fuel cost, the total OEM cost, the total charter cost, and the mobilisation cost account for $1.7 \%, 19.3 \%, 77.7 \%$, and $1.3 \%$ of the total O\&M cost, respectively (Figure 8). 
Total O\&M Cost Distribution for 100-turbine Site

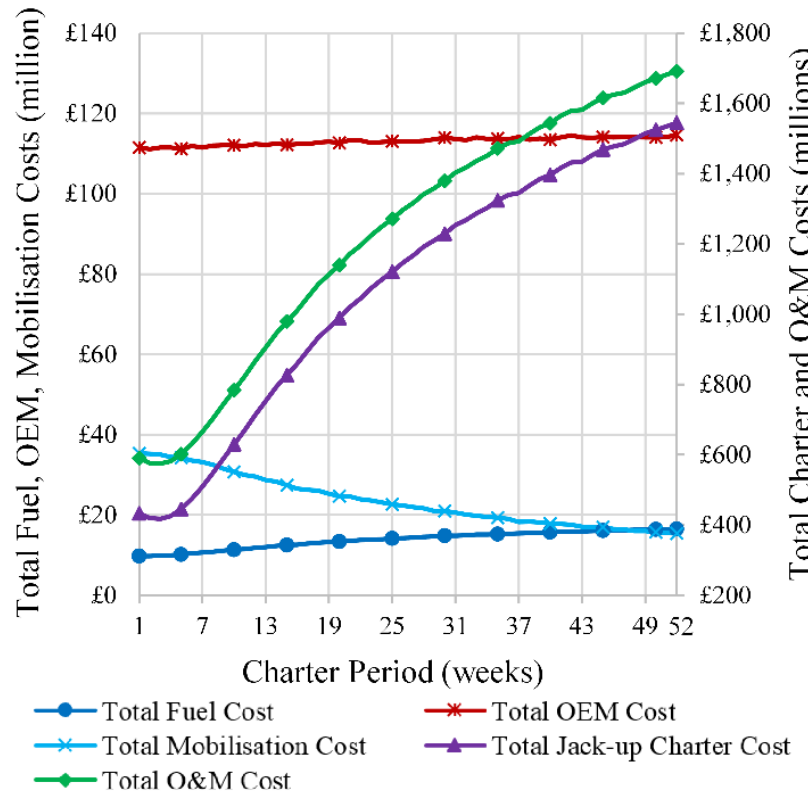

Figure 6: Total O\&M cost distribution for 100-turbine site

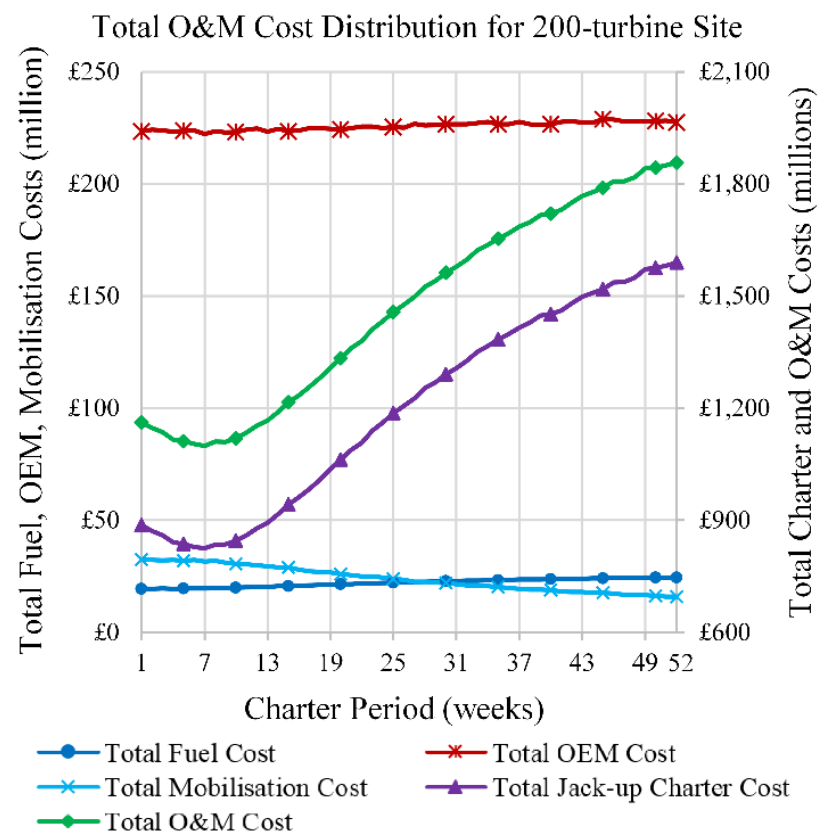

Figure 7: Total O\&M cost distribution for 200-turbine site
Total O\&M Cost Distribution for 300-turbine Site

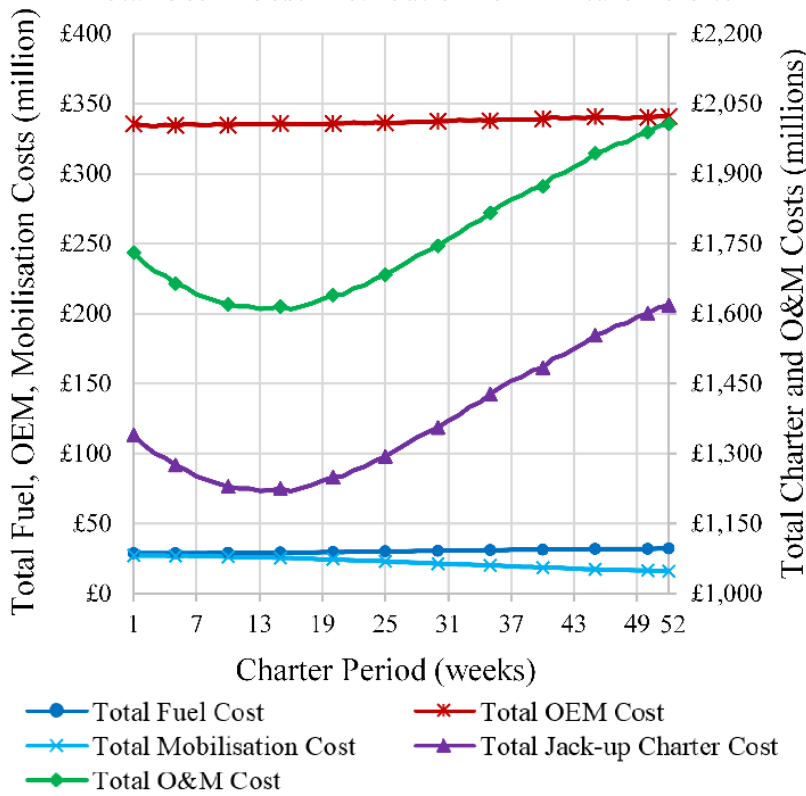

Figure 8: Total O\&M cost distribution for 300-turbine site

It can be identified that the total jack-up vessel charter costs dominate the total O\&M costs in all cases. The charter periods, during which the total jack-up vessel charter costs are minimum, also leads to minimum total O\&M costs in all cases. Due to the fact that the increase in the turbine number requires longer repair period for the jack-up vessels, the charter periods, during which the total O\&M costs are minimum, are shifted right on the graphs. In all cases, the total OEM and the total fuel costs slightly increase when the jack-up vessel is chartered for longer periods. The reason that the total fuel costs increases is the fact that the operational days are increased proportionally when the charter period is increased. The total OEM costs increase because the MTTR values of the components decrease proportional to the charter period. The lower values for MTTR denotes that the components remains in functioning state longer (Figure 9). Due to the fact that if there is a failed component in the turbine, that specific turbine cannot fail again until the failed component is repaired; similarly the failures increase if the turbine remains in the functioning state longer. The total mobilisation costs decrease gradually in all cases, when the charter period is increased. This is because the number of vessel charters decreases subject to the increase in the charter period. 


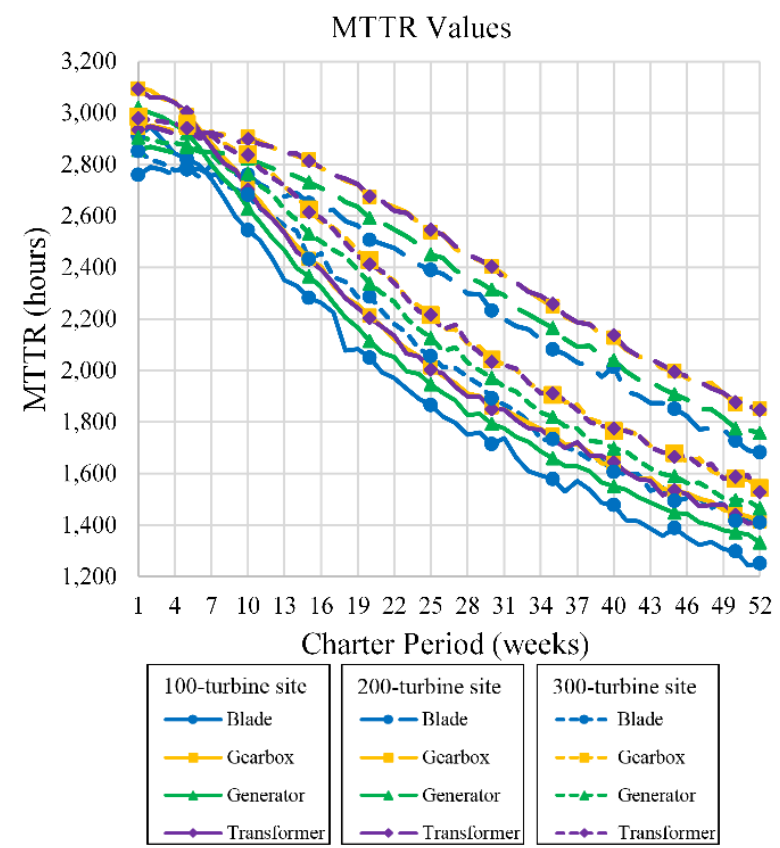

Figure 9: Component MTTR values

Figure 10 presents the change of the total charter rate distribution over increasing charter length. In all cases, the demurrage, which is paid as a penalty additional to the regular charter payment, decreases when the charter length is increased. On the contrary, the regular charter payment is increased, due to the fact that regular charter payments are directly proportional to the defined charter period. The summation of demurrage and regular charter payments are equal to the total jack-up vessel charter rates demonstrated in Figure 6-8.

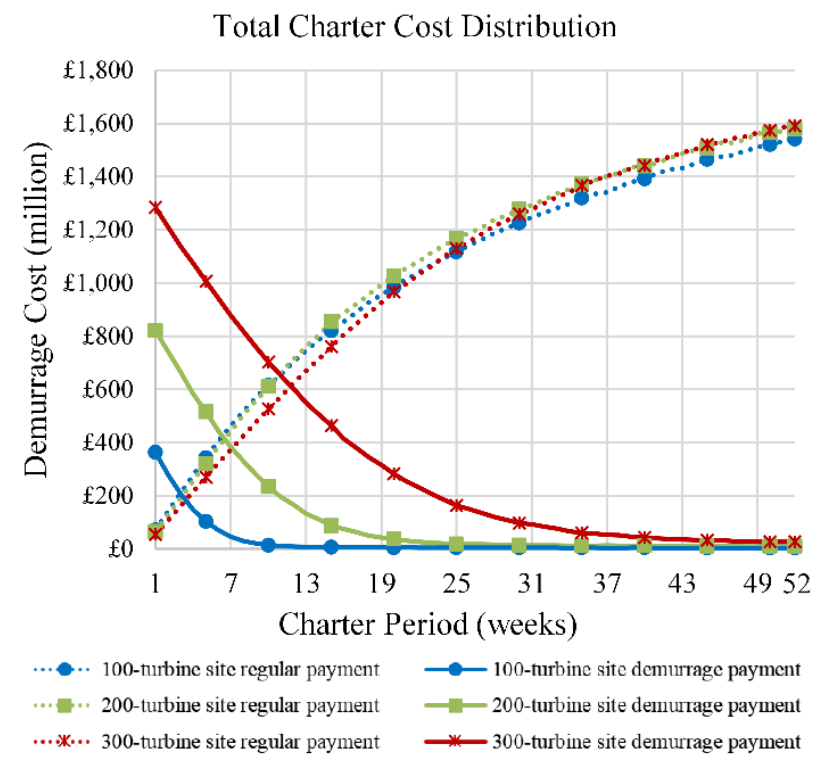

Figure 10: Total charter cost distribution
The vessel utilisation drops significantly for the 100-turbine case when the charter period is increased (Figure 11). This is because, the number of sequential failures in the 100-turbine case is relatively low to keep the chartered vessel in operating state. Instead, the jack-up vessel stays mostly in the port when the charter period is increased. Although the utilisation values decrease in the 200-turbine and 300-turbine cases, the slope of the curves are not as steep as the 100-turbine case; considering the fact that the number of failures increases due to the increase in the wind farm size. It can be also identified that the shape of the curves change from linear to exponential when the size of the wind farm decreases, which shows that the wind farm size or eventually the number of sequential failures significantly influence the vessel utilisation and the effect becomes more dominant in relatively smaller offshore wind farms.

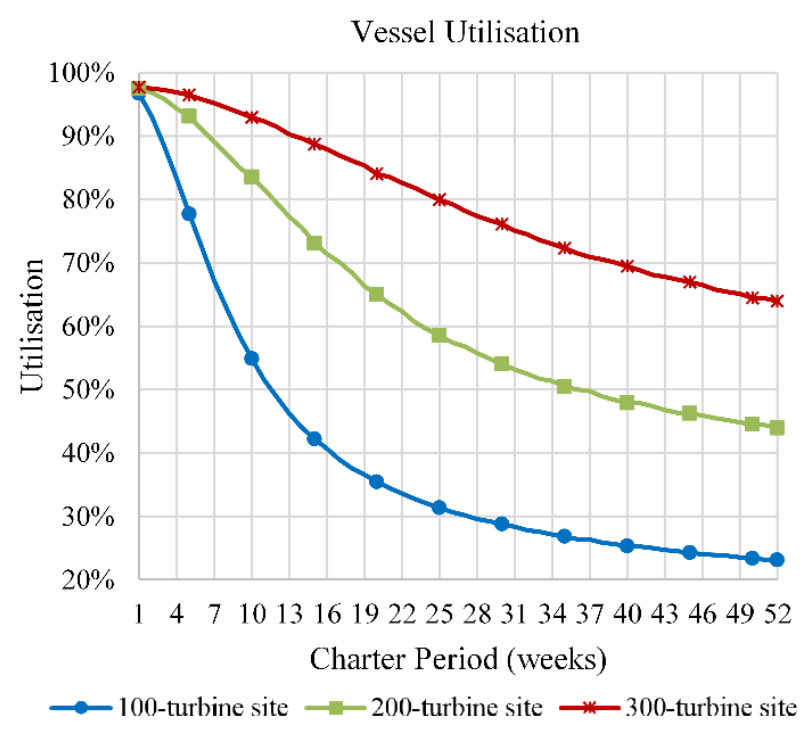

Figure 11: Jack-up vessel utilisation

The total O\&M cost/MWh is the key parameter in the identification of optimum charter period for jack-up vessel; because the total O\&M cost per unit power production reflects all the variations both in terms of cost increase/decrease and power production increase/decrease (Figure 12). It is important to highlight that the proportion of the economic benefit from producing more energy by increasing the availability does not always lead to higher profits since it may not compensate the increase in the total O\&M costs. In this context, the optimum short-term charter periods and the total 
O\&M cost can be identified as 3 weeks$£ 39.2 / \mathrm{MWh}, 7$ weeks-£37.4/MWh, and 16 weeks$£ 36.2 / \mathrm{MWh}$ for 100-turbine, 200-turbine, and 300turbine cases, respectively.

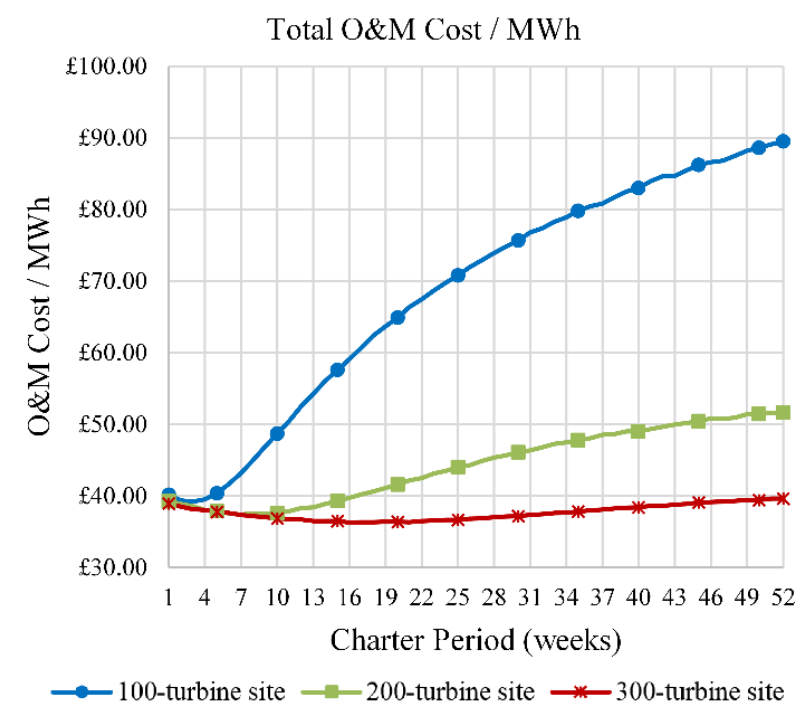

Figure 12: Total O\&M cost per MWh

It can be noticed that these optimum short-term charter periods are identical to the short-term charter periods that the total O\&M costs are minimum. The availability and revenue increase up to these optimum periods compensate the increase in the total O\&M costs; however the proportion of loss starts to increase if the jack-up vessel is chartered for periods longer than optimum length. As for the total O\&M cost values, the charter lengths that the O\&M cost/MWh are minimum, are shifted right with the increase in the wind farm size. Regardless of the charter period, the total O\&M cost/MWh remains lower for larger wind farm cases, due to the fact that the total power production and the total revenue is higher for larger wind farms.

As a concluding investigation, the major aspects are compared to identify whether long-term chartering or short-term/spot market chartering is cost effective for the specified cases (Table 8). If the short-term charter alternative is considered, the total O\&M cost values at the optimum charter periods for each wind farm case (smaller to larger) are $£ 39.2 / \mathrm{MWh}, £ 37.4 / \mathrm{MWh}$, and $£ 36.2 / \mathrm{MWh}$, respectively. On the other hand, £67.6/MWh, $£ 37.1 / \mathrm{MWh}$, and $£ 27.1 / \mathrm{MWh}$ are expected to be paid, if the jack-up vessel is chartered for long-term. In this case, the long-term charter alternative is more cost effective for 200-turbine and 300-turbine cases; on the other hand short-term charter is more beneficial for the 100-turbine wind farm.

\section{Concluding remarks and future work}

In this study, an extensive jack-up charter period optimisation methodology is introduced for offshore wind farm O\&M activities towards optimum O\&M cost and maximum power production. Climate parameters, failure characteristics of turbine components, the specification of jack-up vessels are simulated within the operational phase of three offshore wind farms. The results are demonstrated to support the decision making related to the maintenance and logistic strategy. The consequences of the variations in the defined attributes can be assessed and the decision, which brings financial and operational benefits, can be selected.

In this context, the influence of the vessel chartering strategy on the total O\&M costs can be noticed. Considering the final results in Table 8 , the total O\&M costs can be decreased by $41.9 \%$ for a 100-turbine wind farm (from £67.6/MWh to $£ 39.2 / \mathrm{MWh}$ ), $0.6 \%$ for a 200-turbine wind farm (from $£ 37.4 / \mathrm{MWh}$ to $£ 37.1 / \mathrm{MWh}$ ), and $25.1 \%$ for a 300-turbine wind farm (from £36.2/MWh to $£ 27.1 / \mathrm{MWh}$ ), respectively, by only optimising the jack-up vessel chartering strategy.

Table 8: Comparison of short-term charter and long-term charter

\begin{tabular}{|c|c|c|c|c|c|c|}
\hline \multirow[t]{3}{*}{ Attribute } & \multicolumn{6}{|c|}{ Number of Turbines } \\
\hline & \multicolumn{2}{|c|}{100} & \multicolumn{2}{|c|}{200} & \multicolumn{2}{|c|}{300} \\
\hline & $\begin{array}{l}\text { Short-term } \\
\text { (3 weeks) }\end{array}$ & Long-term & $\begin{array}{c}\text { Short-term } \\
\text { (7 weeks) }\end{array}$ & Long-term & $\begin{array}{l}\text { Short-term } \\
\text { (16 weeks) }\end{array}$ & Long-term \\
\hline Vessel Utilisation (\%) & 88.3 & 14.4 & 89.0 & 28.8 & 87.9 & 43.2 \\
\hline Total O\&M Cost/MWh (£/MWh) & 39.2 & 67.6 & 37.4 & 37.1 & 36.2 & 27.1 \\
\hline Blade-MTTR (hours) & 2896 & 47.9 & 2800 & 65.9 & 2618 & 95.8 \\
\hline Gearbox-MTTR (hours) & 3054 & 167.9 & 2928 & 184.8 & 2785 & 211.9 \\
\hline Generator-MTTR (hours) & 2983 & 96.1 & 2840 & 112.6 & 2707 & 139.2 \\
\hline Transformer-MTTR (hours) & 3061 & 167.9 & 2912 & 185.7 & 2787 & 213.6 \\
\hline
\end{tabular}


It should be highlighted that the level of operational and financial benefits can vary from project to project. The change in the charter strategy influences the 100-turbine and 300-turbine cases more than 200-turbine case. This is because the total O\&M cost decreased from $£ 1,240 \mathrm{M}$ (including sub-charter revenue) to $£ 574 \mathrm{M}$ while the total power production decreased only $3.3 \%$ for the 100 turbine case, if short-term charter alternative is considered. The total O\&M cost decreased from $£ 1,609 \mathrm{M}$ to $£ 1,491 \mathrm{M}$ (including sub-charter revenue) and production increased by $3.1 \%$ for the 300-turbine case, if long-term charter alternative is considered. On the other hand, chartering the jackup vessel for long-term caused an increase on the total O\&M cost from $1,098 \mathrm{M}$ to $£ 1,365 \mathrm{M}$ (including sub-charter revenue) while the power production for the 200-turbine case increased only by $3.2 \%$; therefore the increase in the power production barely compensates the total O\&M cost increase.

It is envisaged that the jack-up operations cause significant delays mainly due to jack-up mobilisation time. In this respect, chartering the vessel for the entire project lifecycle could be a solution, which would eliminate or minimise the mobilisation time. However, the proportion of the jack-up charter cost to the total O\&M cost can be equal to $80.3 \%$; therefore chartering the vessel for a long period increases the total O\&M cost and eventually the total financial loss drastically. Especially for the small wind farms, chartering a jack-up vessel for the entire project lifecycle is not feasible, considering the fact that vessel owners request considerably higher charter rates and expect high profits as in the offshore oil and gas industry.

On the other hand, long-term chartering and purchasing options can be feasible for the next generation larger sites in the UK, Germany and Denmark. In this respect, regional collaborations between different operating companies, which should also be supported by national and international legislation, can be the solution towards optimised jack-up vessel cost and maximised utilisation throughout the chartered period.

It is believed that another direction of further research can be the investigation of failure rate variability (high-low), mobilisation time, mobilisation cost, and demurrage cost influence on the identification of jack-up vessel strategy; so more accurate calculations can be performed. Since only major component failures are considered in this study, it is also important to investigate the influence of the minor component failures on the selection of overall O\&M strategy. Furthermore, offshore wind O\&M fleets with multiple jack-up vessels and hybrid/seasonal vessel chartering strategies can be necessary to sustain the power production in the future; therefore, bespoke methodologies are required to be developed for very large sites.

\section{Acknowledgement}

Results were obtained using the EPSRC funded ARCHIE-WeSt High Performance Computer (www.archie-west.ac.uk). EPSRC grant no. EP/K000586/1.

\section{References}

Bechrakis, D.A., Sparis, P.D., 2000. Simulation of the Wind Speed at Different Heights Using Artificial Neural Networks. Wind Engineering 24 (2), 127-136.

Blanco, M.I., 2009. The economics of wind energy. Renewable and Sustainable Energy Reviews 13 (67), 1372-1382.

Burton, T., Jenkins, N., Sharpe, D., Bossanyi, E., 2011. Wind Energy Handbook. Wiley, Oxford, UK.

Dalgic, Y., Lazakis, I., Turan, O., 2014. Vessel charter rate estimation for offshore wind O\&M activities. Developments in Maritime Transportation and Exploitation of Sea Resources, Vol 2, 899-907.

Dinwoodie, I., McMillan, D., Revie, M., Lazakis, I., Dalgic, Y., 2013. Development of a Combined Operational and Strategic Decision Support Model for Offshore Wind. Energy Procedia 35 (0), 157166.

DNV, 2004. DNV Offshore Standard DNV-OSJ101 Design of Offshore Wind Turbine Structures, Høvik, Norway, p. 213.

Edkins, M., Dunkley, R., 1998. Laytime and demurrage in the oil industry. LLP, London. 
EWEA, 2011. Wind In Our Sails - The Coming Of Europe's Offshore Wind Energy Industry, in: Azau, S., Casey, Z. (Eds.). European Wind Energy Association, Brussels, Belgium.

Fingersh, L., Hand, M., Laxson, A., 2006. Wind Turbine Design Cost and Scaling Model. National Renewable Energy Laboratory.

Fırtın, E., Güler, Ö., Akdağ, S.A., 2011. Investigation of wind shear coefficients and their effect on electrical energy generation. Applied Energy 88 (11), 4097-4105.

Gryning, S.E., Batchvarova, E., Brummer, B., Jorgensen, H., Larsen, S., 2007. On the extension of the wind profile over homogeneous terrain beyond the surface boundary layer. Boundary-Layer Meteorology 124 (2), 251-268.

Gualtieri, G., Secci, S., 2012. Methods to extrapolate wind resource to the turbine hub height based on power law: A 1-h wind speed vs. Weibull distribution extrapolation comparison. Renewable Energy 43 (0), 183-200.

Halvorsen-Weare, E.E., Gundegjerde, C., Halvorsen, I.B., Hvattum, L.M., Nonås, L.M., 2013. Vessel Fleet Analysis for Maintenance Operations at Offshore Wind Farms. Energy Procedia 35 (0), 167-176.

Junginger, M., Faaij, A., Turkenburg, W.C., 2004. Cost reduction prospects for the offshore wind energy sector. Wind Engineering 28 (1), 97-118.

Kaiser, M.J., Snyder, B., 2010. Offshore Wind Energy Installation and Decommissioning Cost Estimation in the U.S. Outer Continental Shelf. Dept. of the Interior, Bureau of Ocean Energy Management, Regulation and Enforcement, Virginia, USA.

Kaldellis, J.K., Kapsali, M., 2013. Shifting towards offshore wind energy-Recent activity and future development. Energy Policy 53 (0), 136-148.

Krohn, S., Morthorst, P.-E., Awerbuch, S., 2009. The Economics of Wind Energy. EWEA, Brussels, Belgium.

Lackner, M.A., Rogers, A.L., Manwell, J.F., McGowan, J.G., 2010. A new method for improved hub height mean wind speed estimates using short- term hub height data. Renewable Energy 35 (10), 2340-2347.

Lazakis, I., Turan, O., Rosendahl, T., 2013. Modelling of vessel and equipment cost for the maintenance activities of an offshore tidal energy array, Proceedings of the PRADS2013, Changwon City, Korea.

Lindqvist, M., Lundin, J., 2010. Spare Part Logistics and Optimization for Wind Turbines. Uppsala Universitet, Uppsala, Sweden.

Manwell, J.F., McGowan, J.G., Rogers, A.L., 2009. Wind energy explained : theory, design and application. John Wiley, Chichester, UK.

MPI Offshore, 2013. MPI Resolution - Vessel Specification.

Musial, W., Thresher, R., Ram, B., 2010. Largescale offshore wind energy for the United States: assessment of opportunities and barriers. National Renewable Energy Laboratory.

Pirrong, S.C., 1993. Contracting Practices in Bulk Shipping Markets - a Transactions Cost Explanation. Journal of Law \& Economics 36 (2), 937-976.

Rademakers, L.W.M.M., Braam, H., 2002. O\&M Aspects of the 500 MW Offshore Wind Farm at NL7. DOWEC Project, Netherlands.

Rademakers, L.W.M.M., Braam, H., Zaaijer, M.B., Van Bussel, G.J.W., 2003. Assessment and optimisation of operation and maintenance of offshore wind turbines, Proceedings of the European Wind Energy Conference, 16-19 June, Madrid, Spain.

Santos, F.P., Teixeira, A.P., Soares, C.G., 2014. Influence of logistic strategies on the availability and maintenance costs of an offshore wind turbine, Safety, Reliability and Risk Analysis: Beyond the Horizon.

Staffell, I., 2012. Wind Turbine Power Curves, London, UK.

The Crown Estate, 2012. Offshore Wind Cost Reduction Pathways Study, London, UK.

The Crown Estate, 2014. Jack-up vessel optimisation - Improving offshore wind 
performance through better use of jack-up vessels in the operations and maintenance phase, London, UK.

Van Bussel, G.J.W., Zaaijer, M.B., 2001. Reliability, availability and maintenance aspects of large-scale offshore wind farms, a concepts study, Proceedings of MAREC Marine Renewable Energies Conference, Newcastle, UK, pp. 119-126.

Wilson, J.F., 2010. Carriage of goods by sea, 7th ed. ed. Longman, Harlow.

WindPower Offshore, 2012. Global Offshore, Special Report, London, UK. 